\title{
Microenvironment-Centred Dynamics in Aggressive B-Cell Lymphomas
}

\author{
Matilde Cacciatore, ${ }^{1}$ Carla Guarnotta, ${ }^{1}$ Marco Calvaruso, ${ }^{1}$ Sabina Sangaletti, ${ }^{2}$ \\ Ada Maria Florena, ${ }^{1}$ Vito Franco, ${ }^{1}$ Mario Paolo Colombo, ${ }^{2}$ and Claudio Tripodo ${ }^{1}$ \\ ${ }^{1}$ Dipartimento di Scienze per la Promozione della Salute, Sezione di Anatomia Patologica, Università degli Studi di Palermo, \\ 90127 Palermo, Italy \\ ${ }^{2}$ Dipartimento di Oncologia Sperimentale, Unità di Immunologia Molecolare, IRCCS Fondazione Istituto Nazionale Tumori, \\ 20133 Milano, Italy
}

Correspondence should be addressed to Mario Paolo Colombo, mariopaolo.colombo@istitutotumori.mi.it and Claudio Tripodo, tripodo@unipa.it

Received 14 October 2011; Accepted 27 October 2011

Academic Editor: Lorenzo Leoncini

Copyright () 2012 Matilde Cacciatore et al. This is an open access article distributed under the Creative Commons Attribution License, which permits unrestricted use, distribution, and reproduction in any medium, provided the original work is properly cited.

\begin{abstract}
Aggressive B-cell lymphomas share high proliferative and invasive attitudes and dismal prognosis despite heterogeneous biological features. In the interchained sequence of events leading to cancer progression, neoplastic clone-intrinsic molecular events play a major role. Nevertheless, microenvironment-related cues have progressively come into focus as true determinants for this process. The cancer-associated microenvironment is a complex network of nonneoplastic immune and stromal cells embedded in extracellular components, giving rise to a multifarious crosstalk with neoplastic cells towards the induction of a supportive milieu. The immunological and stromal microenvironments have been classically regarded as essential partners of indolent lymphomas, while considered mainly negligible in the setting of aggressive B-cell lymphomas that, by their nature, are less reliant on external stimuli. By this paper we try to delineate the cardinal microenvironment-centred dynamics exerting an influence over lymphoid clone progression in aggressive B-cell lymphomas.
\end{abstract}

\section{Introduction}

B-cell malignancies represent a heterogeneous group of diseases characterized by different biological features and clinical behaviour, the latter ranging from indolent to highly aggressive. As for most neoplasms, the natural course of Bcell malignancies is characterized by tumour progression, featured by a flow of events leading to the enhancement of proliferative and invasive capabilities, towards the establishment of a more aggressive phenotype. Even if most of the processes involved in cancer progression are inherent to the neoplastic clone, this event is, actually, the result of an articulated mechanism, which seems to require the constant crosstalk between neoplastic cells and the faulty surrounding microenvironment. An ever-increasing amount of evidences suggest that this bijective relationship is a prime determinant of cancer natural history and evolution. Much has been so far discovered about the role of tumour intrinsic mechanisms of neoplastic progression, and the focus of research has been progressively shifting toward the study of microenvironment-centred dynamics. Cancer-associated microenvironment represents a multifaceted entity, which not only provides structural support to neoplastic cells (proper stroma) but also acts as a "fertile soil" that, through humoral factors (bioactive molecules such as cytokines, chemokines, and adhesion molecules), nonmalignant cellular elements of the stroma (fibroblasts and endothelial cells) and the immune system (macrophages, mast cells, $\mathrm{B}$ and $\mathrm{T}$ lymphocytes) fosters tumour clone survival and expansion, local invasion/spreading, and escape from the immunological response.

The relative contribution of these branches of the tumour microenvironment may vary in the diverse tissues and organs in which lymphomas arise as well as in different lymphoma 
histotypes, yet, their relevance is proved by their influence over the disease clinical outcome.

The contribution of microenvironment to lymphoma progression has been deeply investigated in indolent lymphomas (ILs), comprising chronic lymphocytic leukaemia/small lymphocytic lymphoma (CLL/SLL), lymphoplasmacytic lymphoma (LPL), Marginal zone lymphoma (MZL), and follicular lymphoma (FL), all sharing common features such as low proliferative rate of neoplastic cells and long time to disease progression and/or treatment.

ILs are indeed characterized by a constant crosstalk with the surrounding microenvironment, which plays a role in their pathogenesis and that eventually affects several aspects of their natural history.

A prototypical example of the influence of tumour microenvironment over lymphoma progression is provided by CLL. It has been shown that CLL clones characterized by $\mathrm{CD} 38$ and $\mathrm{CD} 49 \mathrm{~d}$ expression, harbouring an unfavourable prognosis, are able to attract $\mathrm{CD} 68+$ monocytes (macrophages) at site of infiltration, by CCL3 and CCL4 chemokines synthesis.

Macrophages (Ms), recruited by the neoplastic cells, in turn, release proinflammatory mediators such as TNF, inducing upregulation of the vascular cell adhesion molecule VCAM-1 on the surrounding stroma; the following VCAM$1 / C D 49 d$ binding significantly increases neoplastic cell proliferation and survival [1]. Such an interchained sequence of events involving the CLL stroma thus represents a direct link with the acquisition of a clinically appreciable aggressive pace of the disease, providing a precious insight into the potential influence of microenvironment-centred dynamics over disease course.

The pressure of immune-cell-engendered stromal changes over lymphoid clone progression can be identified in ILs other than CLL and also involving, besides Ms, other cells of the innate and adaptive immune system. Indeed, bone marrow (BM) mast cells (MCs) are commonly found in association with neoplastic BM infiltrates in patients with LPL, supporting tumour expansion through vigorous CD154-CD40 stimulation [2].

In FL, neoplastic cells benefit of the association with follicular helper T cells (Th), follicular dendritic cells (FDCs), Ms and FOXP3-expressing T regulatory cells (Tregs), for the shaping of an aberrant stromal microenvironment permissive for germinal centre (GC), neoplastic B cells $[3,4]$, also T helper 17 (Th17) and other IL-17-producing cells are likely to play a role in this setting.

In line with their strong reliance from lymphomatous/leukemic microenvironment, ILs show a diversified degree of tropism for stromal niches, which they colonize and subdue. Relevant examples are provided by FL cells tropism for osteoblastic/paratrabecular BM niches, rich in cellular and extracellular components (Jagged-1 Notch ligand, $\beta$-lintegrins, type I collagen, osteopontin, and SPARC matricellular proteins) shared by the GC environment itself [5], and by splenic MZL cell homing to sinusoidal vascular niches of the BM and spleen sharing chemoattractive and adhesive signals (CXCL-12, hyaluronan, and ICAM-1) $[6,7]$.
The tight relation and mutual influence between neoplastic cells and their stromal microenvironment, which we have outlined for ILs, may appear less germane to aggressive lymphomas that, by their nature, show a stronger proliferative attitude and a high invasive behaviour. In these malignancies, the microenvironment role has been marginally considered in tumour progression and, therefore, poorly studied.

The aim of this paper is to highlight the actual relevance of the stromal microenvironment in the natural history of B-cell aggressive lymphomas, trying to provide a detailed perspective of the relevant interactions involving bystander immune and mesenchymal cells and extracellular components of the stroma.

\section{Bystander Immune Cells}

The tumour microenvironment is populated by cells of the adaptive and innate immune system that, interacting with cancer cells, may contravene to their primary "guardian" function by actively contributing to tumour onset and progression (Figure 1).

The amount, composition, and location of both adaptive and innate immune system components vary greatly between the different types of malignant lymphoma and exert a diverse influence on the prognosis [8].

T-cell-/histiocyte-rich large B-cell lymphoma (THRL$\mathrm{BCL}$ ) represents a paradigmatic variant in which the neoplastic large B cells constitute a minority of the tumour burden in the context of a dense microenvironment rich in $\mathrm{T}$ cells, with or without histiocytes [9]. Such a picture displays a high degree of homology with that of classical Hodgkin's lymphoma, in which neoplastic cells induce the recruitment of a constellation of immune cells (lymphocytes, granulocytes, Ms, DCs) from the peripheral circulation that, in turn, induce a favourable environment to the neoplasm maintenance and progression [10-12].

Tumour associated macrophages (TAMs) of THRLBCL are recruited within neoplastic infiltrates mainly by clonederived macrophage chemotactic proteins (MCPs) and represent a major component of the infiltrate. Within the cancer-associated microenvironment, TAMs display a peculiar dual-faceted attitude; they can kill tumour cells but at the same time favour their growth by inducing immunosuppression and producing angiogenic factors and metalloproteases [13]. In most aggressive B-cell lymphomas, TAM protumoral function neatly prevails over their participation to antitumour immunity. Specifically, in THRLBCL IFN- $\gamma$-induced TAM activation determines the synthesis of the chemoattractant protein CCL-8 (MCP-2) and of the immunomodulatory molecule indoleamine 2,3-dioxygenase (IDO), that give rise to a self-feeding immunosuppressive loop [14].

A significant $\mathrm{M}$ infiltration is observed in other aggressive B-cell lymphomas such as in Burkitt's lymphoma (BL), in which Ms are functionally involved in neoplastic apoptotic cell engulfment and are stimulated by IL-10 to the synthesis 


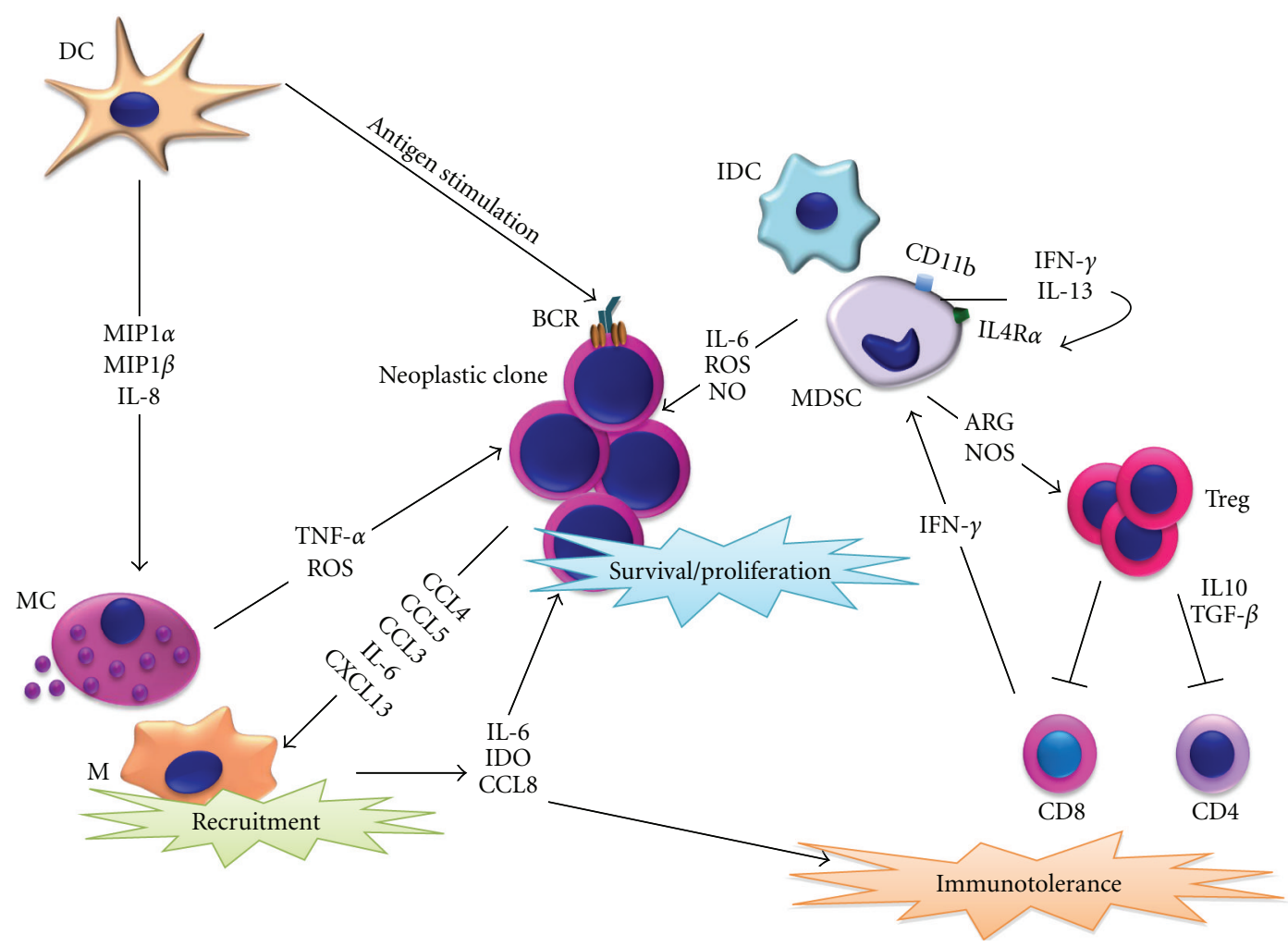

FIGURE 1: Immune system cells, both adaptive and innate, engender a fertile microenvironment through direct interaction and release of factors in the milieu. (M: monocyte/macrophage; MC: mast cell; DC: dendritic cell; IDC: immature dentritic cell; MDSC: myeloid derived suppressor cell; T reg: T regulatory lymphocyte. Black arrows indicate activation pathways. Red lines indicate inhibitory pathways).

and release of B-cell trophic factors such as BAFF/BLyS [15]. In addition to directly stimulate neoplastic B cells, CD68expressing Ms induce activation of the neighbouring mesenchymal cells as demonstrated by VCAM-1 upmodulation in areas of prominent $M$ infiltration (Figures 2(a) and 2(b)).

Similarly, in diffuse large B-cell lymphoma (DLBCL), neoplastic cells recruit $\mathrm{T}$ cells and $\mathrm{CD} 14+$ monocytes by CCL-5 release, also engendering a histiocyte-enriched microenvironment [16]. Besides local synthesis of soluble mediators active on neoplastic B cells, infiltrating Ms and other professional antigen-presenting cells (APCs) can support neoplastic B-cell proliferation and rescue from apoptosis by sustained B-cell-receptor (BCR) stimulation [17].

BCR signalling pathway can be triggered in neoplastic cells by canonical antigen ligation or by antigen-independent adhesive signals modifying the actin cytoskeleton and in both cases involves the activation of the Syk kinase [18]. BCR stimulation by environment-generated signals can be relevant for the fitness of neoplastic B cells, yet, in several aggressive B-cell lymphomas, as in DLBCL, constitutive activation of the BCR pathway (i.e., tonic signalling) can be observed, which is not dependent on external stimuli [19, 20]. On these bases, inhibition by Syk targeting, irrespectively of the neoplastic cell-intrinsic or cell-extrinsic source of BCR stimulation, could be envisaged as an appealing therapeutic prospect [21].
Among monocytic/macrophagic CD14-expressing cells recruited by DLBCL clones, intratumoral precursors of dendritic cells (DCs) have been identified basing on their expression of the DC marker DC-SIGN and on the acquisition of DC morphology. DCs found within tumour infiltrates are commonly "frozen" in an immature status (iDCs) by soluble factors of the tumour milieu such as IL-4, IL-6, GM-, and M-CSF. iDCs are also recruited from the BM myeloid cell reservoir through CCL-3 and CCL-4 chemokine interaction with CCR-1/-2/-5 receptors and on their turn participate to the recruitment of other myeloid cells at sites of infiltration (e.g., by IL-8, RANTES, TARC, and MDC) [22, 23]. Among BM-derived myeloid cells that might be coopted by neoplastic $\mathrm{B}$ cells or bystander cells in the lymphomaassociated microenvironment, a relevant population is represented by myeloid-derived suppressor cells (MDSCs). With iDCs, MDSCs share an immature myeloid phenotype and are characterized by the expression of the CD11b, CD33, and IL4r. Both iDCs and MDSCs empower the regulatory milieu associated with the expanding clone by the inhibition of T-cell responses through nitric oxide (NO) and reactive oxigen species (ROS) release and induction of Treg skewing. It is conceivable that the restoration of the physiologic crosstalk between DCs (or other APCs) and T cells, or the functional inactivation of such myeloid regulatory cells [24, 25], might induce effective Th-1-oriented cytotoxic responses against the B-lymphoid clone. Indeed, a dense 


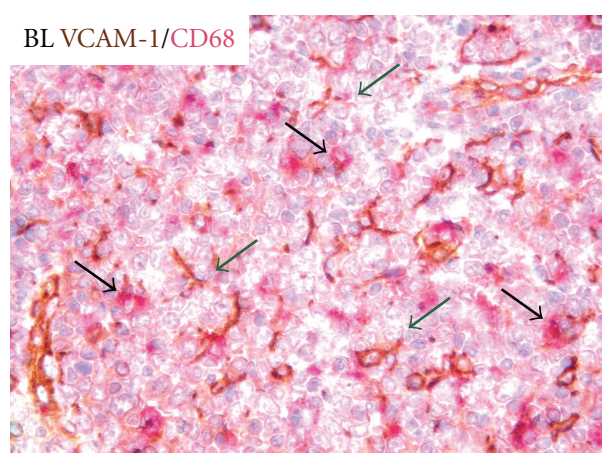

(a)

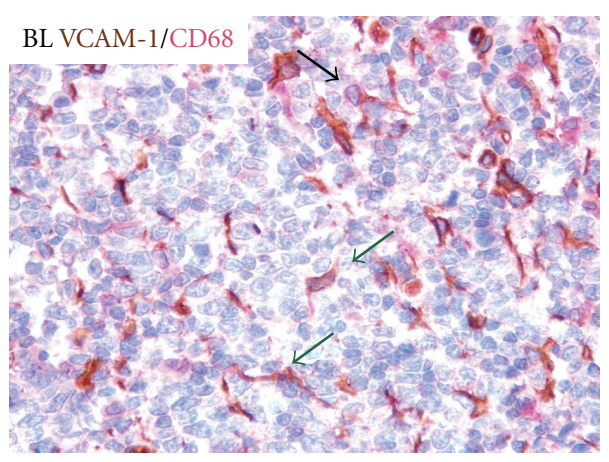

(b)

FIgURE 2: Adhesion molecule VCAM1-expressing mesenchymal cells (green arrows) form a denser meshwork in BL cases rich in CD68expressing macrophages (black arrows) as compared with cases showing scattered CD68-expressing macrophages. (VCAM and CD68 immunohistochemical stain performed with streptavidin-biotin peroxidase complex system, original magnification 400x).

cytotoxic T-cell infiltrate spatially associated with CD21expressing FDC meshwork has been correlated with better survival and a higher complete remission rate in highrisk DLBCL [26], thus suggesting a favourable influence of effector $\mathrm{T}$ cells populating the lymphoma environment. However, other studies have shown that dense infiltrates of activated cytotoxic $\mathrm{T}$ cells in nodal DLBCL correlate with poor survival [27] indicating that the actual outcome of Tcell infiltration is indeed puzzling and variable.

If the interpretation of the contribution of infiltrating $\mathrm{T}$ cells to the composition of the lymphoma microenvironment appears rather problematic, this is particularly true for Tregs [4, 28, 29]. In DLBCL, the prognostic significance of infiltrating Tregs has proved quite controversial, since the amount of Tregs associated with lymphoma infiltrates has been found to independently correlate with a good $[30,31]$ or dismal prognosis (or found unrelated with prognosis) $[28,31]$ by different Authors. The controversial results of Treg prognostic influence in DLBCL has been interpreted in light of the heterogeneity of settings and methods adopted for Treg assessment [28], yet they probably have a true biological explanation.

Tregs modulate the activity of both CD4+ and CD8+ effector populations through the release of IL-10 and TGF$\beta 1$. Therefore, they can contribute to the immune escape of the neoplastic clone producing a detrimental influence on outcome while, at the same time, depriving neoplastic cells from beneficial proinflammatory stimuli induced by other lymphoma-infiltrating cells. Moreover, the above-mentioned analyses of Treg influence in the lymphoma-associated environment are intrinsically flawed by the assumption that Tregs are "functionally stable" which means not considering their plasticity. In their activity of quenching immune responses by interfering with the activation status of innate (e.g., MCs) and adaptive (e.g., T cells) immune effectors, Tregs are exposed to the pressure of the inflammatory milieu, by which they can be skewed towards other functional fates. We have recently demonstrated that activated MCs can induce contrasuppression of Tregs through the OX40/OX40L axis and IL-6 release in a TGF- $\beta 1$-rich environment towards the generation of proinflammatory Th17 cells $[32,33]$. In this light, the different prognostic value of FOXP3+ Tregs in GC-type DLBCL where their presence is related with a positive prognostic influence and non-GC DLBCL where, by contrast, an increase of FOXP3+ Tregs directly correlates with an adverse outcome, could be at least partially explained by the marked inflammatory environment engendered in the latter by the abundancy of IL-6- and TNF-producing Ms and MCs [34-36]; this could inhibit the function of Tregs which, in turn, could even boost inflammation favouring Th17 generation [28].

Overall, it is hard to identify a leitmotiv in the functional interactions between neoplastic cells and immune bystander cells of aggressive B-cell lymphomas as the final outcome of such interplay can profoundly vary at discrete stages of the disease course and can be significantly affected by therapy. Nonetheless, aggressive B-cell lymphoid clones, despite their striking proliferative and invasive capabilities, are not disengaged by the influence of the immune microenvironment, which actually represents a reasonable focus for chasing the improvement of treatment efficacy.

\section{The Matter of Vasculogenesis}

Among the different aspects functional to tumour progression characterizing the cross talk between neoplasms and stroma, a remarkable role is played by vasculogenesis. Neo-angiogenesis has been the focus of extensive scientific investigation in the field of cancer research. The generation of new blood vessels not only provides a dedicated blood supply to the tumour, but also represents the hinge of its dissemination, being the most direct route for the colonization of secondary organs.

In aggressive B-cell lymphomas, as in several other cancers, Neo-angiogenesis is the result of a play of forces between neoplastic and stromal elements involving the axis of vascular endothelial growth factors (VEGFs) and their receptors, known to play a central role in this process (Figure 3 ). The synthesis of VEGFs along with the expression of their receptors has been extensively described in DLBCL [37], 


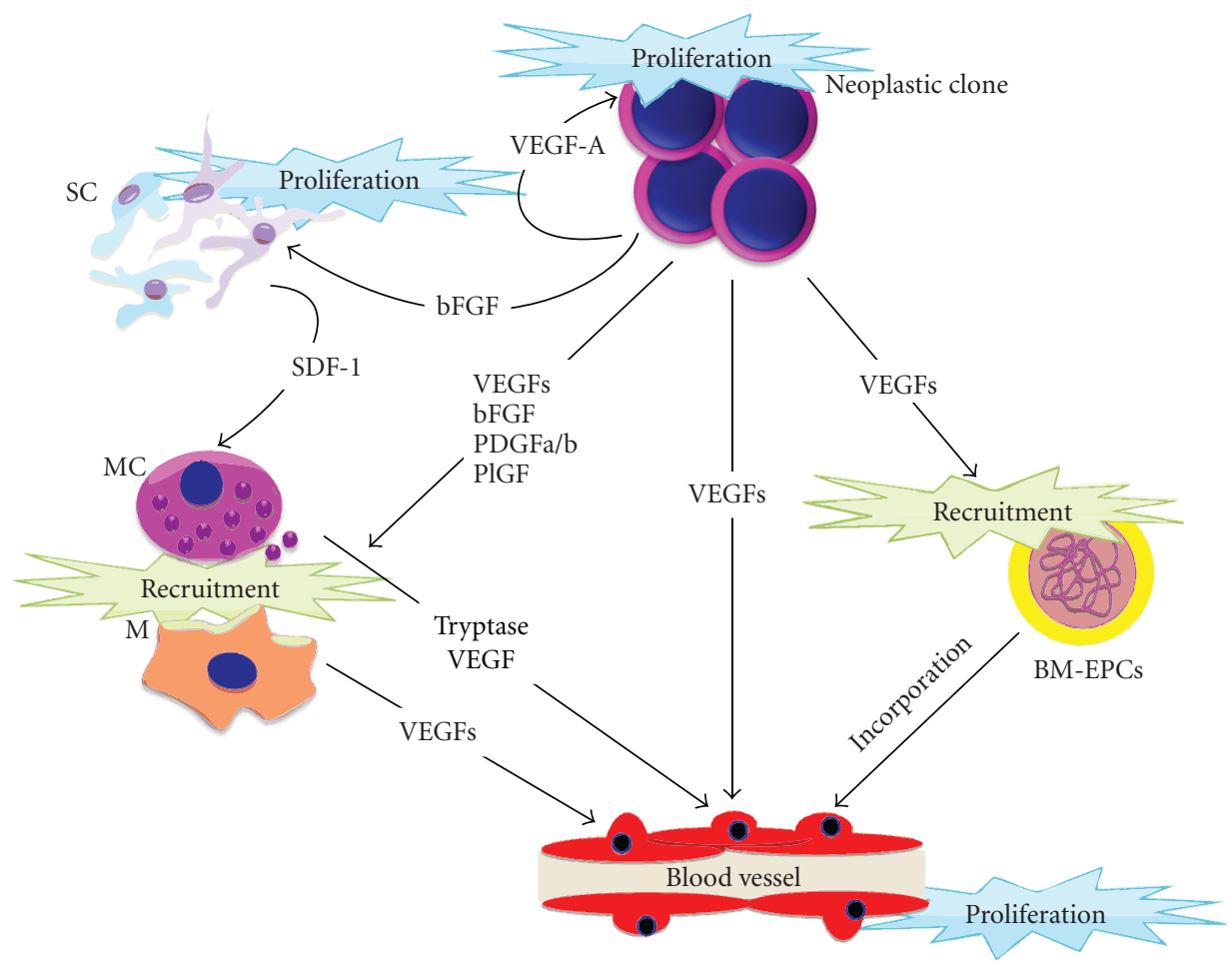

FIGURE 3: Vasculogenesis plays a key role in clone dissemination and represent a the route for organ colonization. (M: monocyte/macrophage; MC: mast cell; SC: stromal cell; BM-EPC: bone marrow derived endothelial progenitor cell. Black arrows indicate activation pathways).

Mantle cell lymphoma (MCL) [38], BL [39], and grade-3 FL [40], being reported as variably associated with the disease aggressiveness.

In such B-cell lymphomas, neoangiogenesis is regulated by an intricated and redundant network of interactions based on the production of growth factors deriving from malignant cells and from accessory cells of the microenvironment. Production of VEGFs (VEGF-A, VEGF-C, VEGF-D) and other angiogenic factors such as the basic fibroblasts growth factor (bFGF), placental growth factor (PlGF), plateletderived growth factors (PDGF-a and PDGF-b) and stromalderived factor-1 (SDF-1) by cancer and stromal cells initiates neoangiogenesis through the contemporary involvement and recruitment of different cytotypes [41]: mature resident endothelial cells receiving direct mitogenic signals stemming from Raf-1-MEK-MAP kinase cascade after interaction with VEGFs [42]; CD68+ monocyte-macrophages and other accessory cells such MCs [43, 44], further enriching the microenvironment by the release of bFGF, PDGF, members of the VEGF family, proteases (e.g., MC-tryptase, matrix metalloproteases), and proinflammatory mediators (IL-1, IL-6, IL-8, and TNF) [45-47]; BM-derived endothelial progenitor cells and BM mesenchymal stem cells recruited by VEGF and SDF-1 gradients, amplifying the synthesis of proangiogenic mediators and eventually incorporating into the growing tumour neovasculature [5, 48-50]. Furthermore, neoplastic B lymphocytes directly perceive proangiogenic stimuli through the expression of VEGF receptors (VEGFR-1 and VEGFR-2), which enables them to receive, in an autocrine fashion, proliferation and/or survival signals
[50]. A high expression of VEGF therefore directly links the remodelling of the stromal vascular microenvironment to clone-intrinsic B-cell lymphoma progression. Several studies have been so far focused on the relationship between microvascular density (MVD) of lymphomatous infiltrates, prognosis, and clinical outcome in B-cell lymphomas; in general, MVD scores trend higher in aggressive histotypes including BL and DLBCL, compared with indolent ones [51].

The correlation between MVD and the clinical course of different lymphoma subtypes, however, is not straightforward. In DLBCL, for instance, multiple studies have demonstrated that there are no significant differences in the MVD counts between the long- and short-surviving patients and that MVD score does not correlate with overall survival [52, 53]. Conversely, other experimental evidences have suggested a negative impact of vasculogenesis on DLBCL clinical outcome by demonstrating that MVD increases paralleling tumour progression $[46,54]$.

Differently from DLBCL, in BL the degree of neoangiogenesis is more homogeneously related to the disease progression. BL aggressive behaviour depends on the overexpression of the oncogene $M Y C$, which also acts as an essential promoter of early and persistent growth of blood and lymphatic vessels during tumour progression [55]. Moreover, as demonstrated in a murine model of $\mathrm{BL}, \mathrm{c}-$ MYC-expressing B cells are the major source of the vascular endothelial growth factor [56].

The mechanism through which c-MYC regulates the VEGF axis has not yet been clearly elucidated. c-MYC may conceivably act as a VEGF transcriptional factor [57], and 
recent data suggest that it could control the expression of several mRNAs (such as the one encoding for VEGF) by regulating a broad range of microRNAs [58].

Along with BL, also MCL is characterized by a strong and active neoangiogenetic process. In MCL, neoplastic B cells give rise to an autocrine positive feedback mediated by the VEGF-A/VEGFR-1 axis, which is also sensed by stromal cells of blood and lymphatic vessels expressing VEGFR-2 and VEGFR-3 [59].

The established leading role played by neoangiogenesis in aggressive B-cell lymphomas paved the way to several clinical trials targeting the formation of new blood and lymphatic vessels. Both consolidated and ongoing approaches are based on the administration of different combinations of drugs capable to interfere with the VEGF axis either in a direct or an indirect manner. Examples of these strategies are the use of anti-VEGF-A antibodies (e.g., bevacizumab) in association with chemoimmunotherapy, and the administration of endostatin and anti-CXCR-4 monoclonal antibodies in the prospect of blocking circulating endothelial cell progenitors $[60,61]$.

Neoangiogenesis is intimately involved in the arousal and progression of B-cell neoplastic clones but dissecting its relative contribution to these processes is problematic owing to the strong correlations it displays with almost every other microenvironment-centred process. This apparent limit to the understanding of the true influence of angiogenesis in the setting of aggressive B-cell lymphomas actually represents a precious advantage for antiangiogenic treatments, which are able to interfere with multiple vicious dynamics of the lymphoma-associated microenvironment, including recruitment of accessory cells, recruitment, and integration of mesenchymal and endothelial progenitors as well as with neoplastic B-cell dissemination.

\section{The Extracellular Matrix: More Than Scaffolding}

Extracellular matrix (ECM) has been considered, for many years, an inert scaffold composed by a complex mixture of proteins, proteoglycans, and in some cases of bone mineral deposits, aimed at providing support and anchorage to cells and regulating intercellular communication.

Synthesized by stromal cells, the ECM represents a reservoir for many growth factors and can be digested by enzymes like serine and threonine proteases and matrix metalloproteases to favour homeostatic processes like tissue remodelling and repair [62].

Similarly, the tumour-associated microenvironment undergoes continuous remodelling, and the ECM components, produced and released by tumour and nonneoplastic stromal cells, represent a major vehicle for the tumourstroma crosstalk. Accordingly, ECM components have been implicated in tumor growth, progression, and metastasis both in solid and lymphoid malignancies [63-66].

One notable attempt to investigate the influence of the ECM on aggressive lymphoma behaviour has been performed in the DLBCL setting [65] following the identification of different DLBCL prognostic categories based on the expression of tumour-related genes [67]. The study performed by Lenz et al. [65] explored DLBCL from a stromal perspective and highlighted a group of cases showing a "stromal signature" enriched in ECM genes coding for collagens, laminin, metalloproteases, and matricellular proteins. This signature was related with a more favourable prognosis as compared with that of another group of DLBCL cases that was enriched in genes promoting the "angiogenic switch."

Matricellular proteins are a class of nonstructural ECM proteins endowed of regulatory function during tissue remodelling [68] and cancerogenesis [69]. Among them, SPARC (secreted protein acidic rich in cysteine), thrombospondins, and osteopontin (OPN) have been reported to play a pivotal role in providing proliferative and antiapoptotic signals to cancer cells, influencing their binding to structural matrix components or directly triggering tumour cell surface receptors [70]. Through the engagement of specific integrin receptors or CD44, OPN exerts its pleiotropic function in cancer cell survival, ECM remodelling, cell migration, and metastasis in solid cancers as well as in aggressive B-cell lymphomas [71-75]. One of the mechanisms hypothesized as responsible for the promotion of neoplastic cell survival by OPN relies on its binding to CD44. OPN-mediated CD44 engagement can prevent cell death by activation of the phosphatidylinositol 3-kinase/Akt signaling axis and by inhibition of Fas-induced signals [76, 77]. In breast cancer, OPN is also able to modulate the expression of specific CD44 isoforms [78] such as the CD44v6 and v9 variants, which endorse a negative prognostic significance. Tissue microarray analyses performed in DLBCL cases, demonstrated that the expression of CD44v6 variant was predominant in the activated type of DLBCL and, in CD44 negative cases, correlated with a worse prognosis [79].

Besides interacting with CD44 and integrins expressed on neoplastic cell surface, OPN contributes to moulding the cancer-associated immunological microenvironment by directly inducing Ms recruitment and activation towards amplification of the inflammatory milieu rich in TNF, IL$1 b$, and IL-6 [80, 81]. These dynamics, which have been extensively investigated in many solid tumours like soft tissue sarcomas [82] and breast cancer [83], could also take place in haematological malignancies owing to the critical role played by $\mathrm{OPN}$ in regulating normal and aberrant hematopoiesis [84].

Another matricellular protein, whose multifaceted influence in cancer microenvironment has been progressively delineating, is SPARC. SPARC, also known as osteonectin or BM-40, is a secreted, matricellular glycoprotein exerting an homeostatic function in tissue remodelling, being capable of regulating biological processes like angiogenesis, cell proliferation, collagen deposition, and inflammation [85]. The tissue-normalizing function of SPARC could be extended to cancer with implications for tumour growth, invasion, and metastasis. However, SPARC expression and functions are greatly tissue and context dependent, and their investigation often ingenerates ambiguous results. For example, 


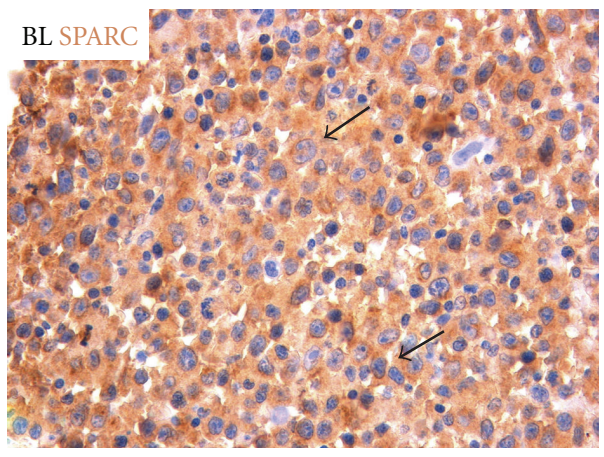

(a)

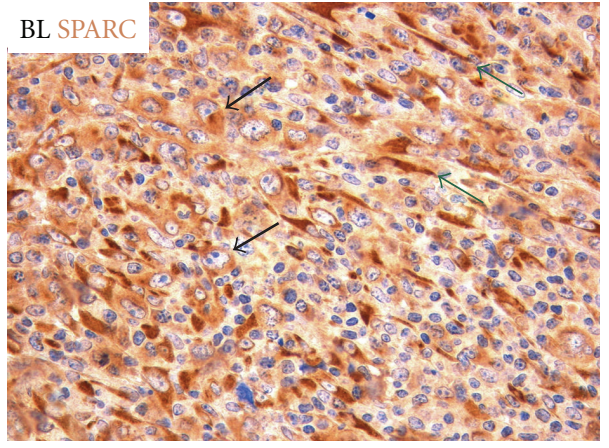

(b)

FIGURE 4: SPARC immunohistochemical analysis of BL cases reveals rather homogeneous expression in neoplastic cells (black arrows) in spite of a variable stroma SPARC reactivity (green arrows). (SPARC immunohistochemical stain performed with streptavidin-biotin peroxidase complex system, original magnification 400x).

in some solid cancers, conspicuous SPARC expression by neoplastic and stromal cells can either promote epithelial-tomesenchymal transition (EMT), and favour tissue invasion and metastasis, or exercise an antiproliferative effect on neoplastic cells, thus limiting cancer progression [86, 87]. Actually, SPARC function in the tumour microenvironment is deeply influenced by its cellular source. SPARC produced by stromal and immune cells may exert diversified influences over the neoplastic clone, the former contributing to cancer stromatogenesis and stromal remodelling while the latter normalizing the inflammatory milieu by negatively regulating immune cell infiltration and activation (e.g., through suppression of the NF-kB pathway) $[75,88]$. SPARC has a paramount importance in the regulation of structural ECM composition [85], in which it participates as a collagen chaperon. The valency of SPARC in regulating the stromatogenesis triggered by neoplastic clones has also a considerable degree of ambiguity. Indeed, SPARC is required for the correct assembly of the collagen meshwork that provides adhesive substrate to cancer cells, yet, it might also inhibit integrin-mediated adhesion and the generation of signals stemming from the integrin-linked kinase activation [89]. Recently, some of us have reported that SPARC gene is highly expressed as part of the GC-related signature of BLs, where it specifically characterizes the endemic BL (eBL) subgroup [90]. Notably, SPARC-, TGF- $\beta$-, and other EMTinducer-derived signals, including those stemming from Notch receptors, converge at the Ras-MAPK pathway, which was found upregulated in BLs in spite of a biased BCR signal initiation [90]. This picture is in line with the cellular program of $\mathrm{BL}$ oriented towards proliferation, migration, and ECM invasion, and poorly reliant on extracellular signals. SPARC protein expression in BL samples consistently marked neoplastic cells but also variably characterized stromal cells of the microenvironment (Figure 4) suggesting a potential involvement of this molecule in stroma-centred dynamics of BL and other GC-associated neoplasms, which haven't been so far explored [90]. In this regard, a role for SPARC produced by FDCs in orchestrating GC T-cell trafficking towards the establishment of Th-17-mediated responses has been recently demonstrated [91].

Besides Osteonectin and SPARC, many other molecules take part to the complex network created by neoplastic cells and ECM components. In BL cell lines, it has been demonstrated that the ECM protein fibronectin, following binding of alphavbeta3-integrin expressed on neoplastic cell surface, activates signal transduction pathways leading to $\mathrm{BL}$ cell proliferation by phosphorylation of the MAP kinase ERK-2 [92]. Similar interactions between integrins and multiple ECM binding partners, namely, vitronectin, laminin, type I and type IV collagen, have been reported to occur in different solid cancer settings and can be also predicted in aggressive lymphomas [93-96].

Matrix metalloproteases (MMPs) were at first identified as mere ECM-regulating components but their involvement in the interplay with factors other than ECM derived, such as growth factors and their receptors, cytokines and chemokines, adhesion receptors, cell surface proteoglycans, and a variety of enzymes has progressively come into evidence $[97,98]$. The expression and production of different MMP subtypes in aggressive B-cell lymphomas may depend not only on the different biology of the neoplastic clone, but could be also determined by the surrounding environment [99]. IL-6 produced by reactive lymphocytes, Ms, endothelial cells, and fibroblasts induces MMP-9 and MMP-2 production that, in aggressive B-cell lymphomas, may lead to a more aggressive clinical behaviour [100].

IL-6 produced in the lymphoma microenvironment also acts as a positive regulator of tissue inhibitor of metalloproteinase (TIMP) expression by neoplastic and stromal cells. TIMPs are capable of inhibiting the activity of MMPs thus keeping the balance between ECM deposition and degradation processes; however, multifaceted and apparently paradoxical actions of TIMPs (i.e., TIMP-1 and TIPM2) have been recently reported, suggesting their direct contribution to lymphoma progression [101].

In fact, TIMP-1 produced by neoplastic B lymphocytes, fibroblasts, and endothelial cells [102] has been shown to 


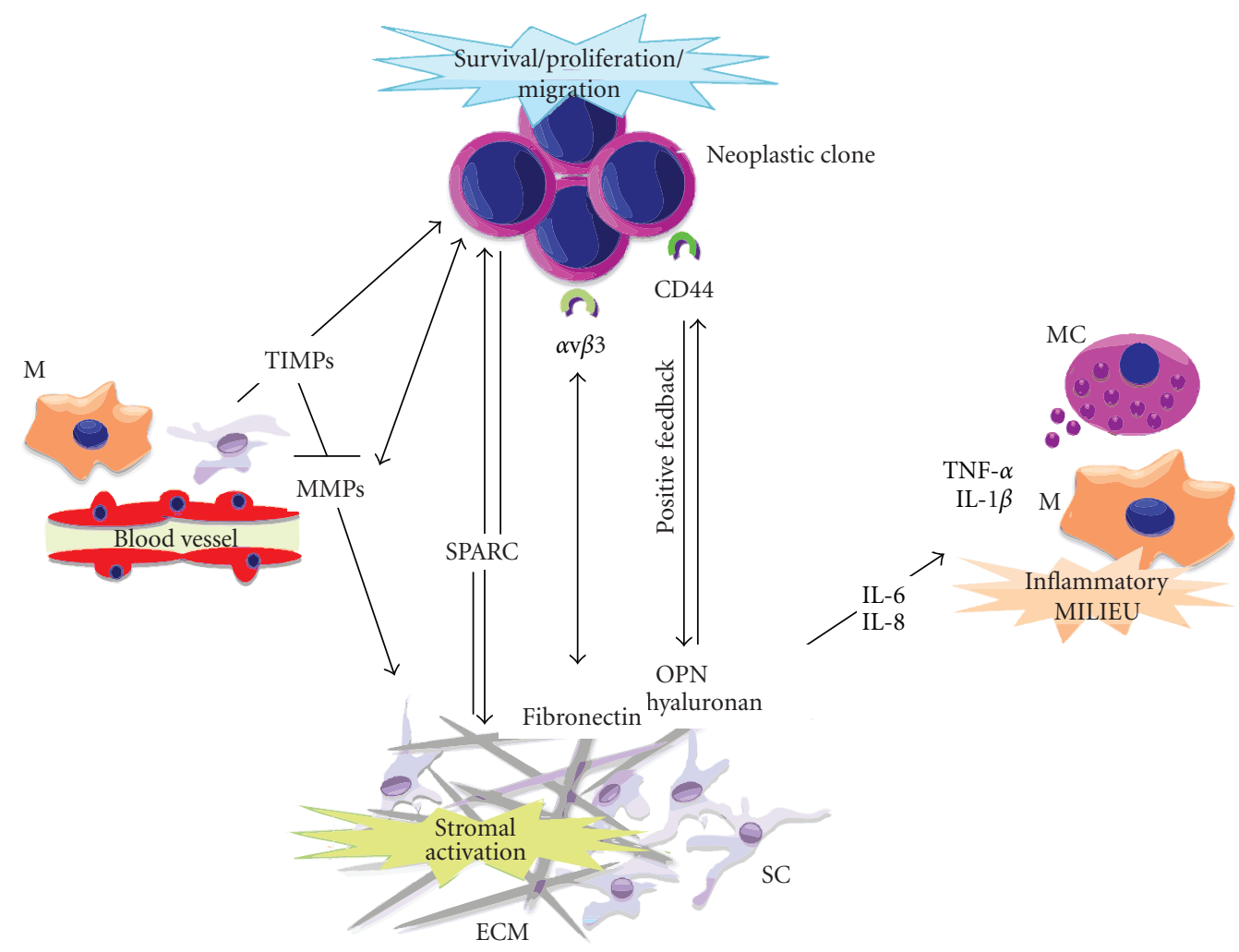

FiguRE 5: Extracellular matrix orchestrates a functional network through its structural and secreted elements. (M: monocyte/macrophage; MC: mast cell; SC: stromal cell; ECM: extracellular matrix. Black arrows indicate activation pathways. Red lines indicate inhibitory pathways).

inhibit germinal centre B-cell apoptosis and promote cancer cell survival in aggressive B-cell lymphomas. The antiapoptotic effect of TIMP-1, which could be considered one of the causes contributing to the poor survival evidenced in some of these cases, is not to ascribe merely to MMP inhibition and/or cell-matrix interactions, but also to the binding of TIMP-1 to other cell-surface receptors, independent of MMP inhibitory function [103].

In BL cells in which TIMP-1 promotes postgerminal centre B-cell differentiation by upregulating MUM-1 and CD138 and downregulating BCL6, its overexpression leads to the activation and expression of STAT3, and to the upregulated expression of cyclin D2, CD44 and BCL-XL, the latter being a target protein of STAT3 with prominent antiapoptotic function [104].

ECM thus emerges as much more than inert scaffolding for lymphomatous cells, representing a major source of direct "rescue" signals and also critically influencing several aspects of the lymphoma-associated environment, such as the trafficking and activation of immune cells (Figure 5). Although strategies aiming at inducing modifications in the ECM components are hardly plausible, owing to the elevated redundancy of the cellular dynamics leading to ECM regulation, ECM should be considered as a precious source of information regarding the biology of the underlying neoplasm, and ECM-related cues (such as miRNAs) should be taken into account as potential cancer-related markers for risk stratification and prognostication [105].

\section{Conclusions}

By delineating the main microenvironmental dynamics that take place in aggressive B-cell lymphomas, we aimed to convey the message of a leading role played by the nonneoplastic lymphoma-associated immunological and stromal elements in influencing the natural history of these highly malignant neoplasms, so far classically considered poorly reliant on the environment. The mutual influence between neoplastic B lymphocytes and their microenvironment results in the enhancement of the proliferative and invasive capabilities of the neoplastic clone and in the concurrent reshaping of the infiltrated tissues.

A deeper understanding of such relationship, through the dissection of its complex dynamics, could prove a successful enterprise for the establishment of multitargeted therapeutic approaches and for the identification of new prognostic factors reflective of the clone-extrinsic biology of these B-cell lymphomas.

\section{References}

[1] A. Zucchetto, D. Benedetti, C. Tripodo et al., "CD38/CD31, the CCL3 and CCL4 chemokines, and CD49d/vascular cell adhesion molecule-1 are interchained bysequential events sustaining chronic lymphocytic leukemia cell survival," Cancer Research, vol. 69, no. 9, pp. 4001-4009, 2009 . 
[2] O. Tournilhac, D. D. Santos, L. Xu et al., "Mast cells in Waldenstrom's macroglobulinemia support lymphoplasmacytic cell growth through CD154/CD40 signaling," Annals of Oncology, vol. 17, no. 8, pp. 1275-1282, 2006.

[3] A. Carbone, A. Gloghini, A. Cabras, and G. Elia, "Differentiating germinal center-derived lymphomas through their cellular microenvironment," American Journal of Hematology, vol. 84, no. 7, pp. 435-438, 2009.

[4] J. Carreras, A. Lopez-Guillermo, B. C. Fox et al., "High numbers of tumor-infiltrating FOXP3-positive regulatory $\mathrm{T}$ cells are associated with improved overall survival in follicular lymphoma," Blood, vol. 108, no. 9, pp. 2957-2964, 2006.

[5] C. Tripodo, S. Sangaletti, P. P. Piccaluga et al., "The bone marrow stroma in hematological neoplasms-a guilty bystander," Nature Reviews Clinical Oncology, vol. 8, no. 8, pp. 456-466, 2011.

[6] A. M. Florena, C. Tripodo, R. Porcasi et al., "Immunophenotypic profile and role of adhesion molecules in splenic marginal zone lymphoma with bone marrow involvement," Leukemia and Lymphoma, vol. 47, no. 1, pp. 49-57, 2006.

[7] L. Trentin, A. Cabrelle, M. Facco et al., "Homeostatic chemokines drive migration of malignant B cells in patients with non-Hodgkin lymphomas," Blood, vol. 104, no. 2, pp. 502-508, 2004.

[8] D. de Jong and G. Enblad, "Inflammatory cells and immune microenvironment in malignant lymphoma," Journal of Internal Medicine, vol. 264, no. 6, pp. 528-536, 2008.

[9] J. Delabie, E. Vandenberghe, C. Kennes et al., "Histiocyterich B-cell lymphoma: a distinct clinicopathologic entity possibly related to lymphocyte predominant Hodgkin's disease, paragranuloma subtype," American Journal of Surgical Pathology, vol. 16, no. 1, pp. 37-48, 1992.

[10] P. P. Piccaluga, C. Agostinelli, A. Gazzola et al., "Pathobiology of Hodgkin lymphoma," Advances in Hematology, vol. 2011, Article ID 920898, 18 pages, 2011.

[11] D. Aldinucci, A. Gloghini, A. Pinto, R. de Filippi, and A. Carbone, "The classical Hodgkin's lymphoma microenvironment and its role in promoting tumour growth and immune escape," Journal of Pathology, vol. 221, no. 3, pp. 248-263, 2010.

[12] C. Steidl, T. Lee, S. P. Shah et al., "Tumor-associated macrophages and survival in classic Hodgkin's lymphoma," The New England Journal of Medicine, vol. 362, no. 10, pp. 875-885, 2010.

[13] C. Brigati, D. M. Noonan, A. Albini, and R. Benelli, "Tumors and inflammatory infiltrates: friends or foes?" Clinical and Experimental Metastasis, vol. 19, no. 3, pp. 247-258, 2002.

[14] P. van Loo, T. Tousseyn, V. Vanhentenrijk et al., "Tcell/histiocyte-rich large B-cell lymphoma shows transcriptional features suggestive of a tolerogenic host immune response," Haematologica, vol. 95, no. 3, pp. 440-448, 2010.

[15] C. A. Ogden, J. D. Pound, B. K. Batth et al., "Enhanced apoptotic cell clearance capacity and B cell survival factor production by IL-10-activated macrophages: implications for Burkitt's lymphoma," Journal of Immunology, vol. 174, no. 5, pp. 3015-3023, 2005.

[16] C. G. Mueller, C. Boix, W. H. Kwan et al., "Critical role of monocytes to support normal B cell and diffuse large B cell lymphoma survival and proliferation," Journal of Leukocyte Biology, vol. 82, no. 3, pp. 567-575, 2007.

[17] R. Küppers, "Mechanisms of B-cell lymphoma pathogenesis," Nature Reviews Cancer, vol. 5, no. 4, pp. 251-262, 2005.
[18] B. Treanor, D. Depoil, A. Gonzalez-Granja et al., "The membrane skeleton controls diffusion dynamics and signaling through the B cell receptor," Immunity, vol. 32, no. 2, pp. 187-199, 2010.

[19] L. Chen, S. Monti, P. Juszczynski et al., "SYK-dependent tonic B-cell receptor signaling is a rational treatment target in diffuse large B-cell lymphoma," Blood, vol. 111, no. 4, pp. 2230-2237, 2008.

[20] R. E. Davis, V. N. Ngo, G. Lenz et al., "Chronic active B-cellreceptor signalling in diffuse large B-cell lymphoma," Nature, vol. 463, no. 7277, pp. 88-92, 2010.

[21] M. Buchner, C. Baer, G. Prinz et al., "Spleen tyrosine kinase inhibition prevents chemokine- and integrin-mediated stromal protective effects in chronic lymphocytic leukemia," Blood, vol. 115, no. 22, pp. 4497-4506, 2010.

[22] W. W. Lin and M. Karin, "A cytokine-mediated link between innate immunity, inflammation, and cancer," Journal of Clinical Investigation, vol. 117, no. 5, pp. 1175-1183, 2007.

[23] P. Cheng, J. Zhou, and D. Gabrilovich, "Regulation of dendritic cell differentiation and function by Notch and Wnt pathways," Immunological Reviews, vol. 234, no. 1, pp. 105$119,2010$.

[24] P. Serafini, S. Mgebroff, K. Noonan, and I. Borrello, "Myeloid-derived suppressor cells promote cross-tolerance in B-cell lymphoma by expanding regulatory T cells," Cancer Research, vol. 68, no. 13, pp. 5439-5449, 2008.

[25] G. Gallina, L. Dolcetti, P. Serafini et al., "Tumors induce a subset of inflammatory monocytes with immunosuppressive activity on CD8+ T cells," Journal of Clinical Investigation, vol. 116, no. 10, pp. 2777-2790, 2006.

[26] K. C. Chang, G. C. Huang, D. Jones, and Y. H. Lin, "Distribution patterns of dendritic cells and T cells in diffuse large B-cell lymphomas correlate with prognoses," Clinical Cancer Research, vol. 13, no. 22, part 1, pp. 6666-6672, 2007.

[27] J. J. F. Muris, C. J. L. M. Meijer, S. A. G. M. Cillessen et al., "Prognostic significance of activated cytotoxic T-lymhocytes in primary nodal diffuse large B-cell lymphomas," Leukemia, vol. 18, no. 3, pp. 589-596, 2004.

[28] A. Tzankov, C. Meier, P. Hirschmann, P. Went, S. A. Pileri, and S. Dirnhofer, "Correlation of high numbers of intratumoral FOXP3+ regulatory $\mathrm{T}$ cells with improved survival in germinal center-like diffuse large B-cell lymphoma, follicular lymphoma and classical Hodgkin's lymphoma," Haematologica, vol. 93, no. 2, pp. 193-200, 2008.

[29] T. Álvaro-Naranjo, M. Lejeune, M. T. Salvadó et al., "Immunohistochemical patterns of reactive microenvironment are associated with clinicobiologic behavior in follicular lymphoma patients," Journal of Clinical Oncology, vol. 24, no. 34, pp. 5350-5357, 2006.

[30] N. R. Lee, E. K. Song, K. Y. Jang et al., "Prognostic impact of tumor infiltrating FOXP3 positive regulatory $\mathrm{T}$ cells in diffuse large B-cell lymphoma at diagnosis," Leukemia and Lymphoma, vol. 49, no. 2, pp. 247-256, 2008.

[31] S. Hasselblom, M. Sigurdadottir, U. Hansson, H. NilssonEhle, B. Ridell, and P. O. Andersson, "The number of tumour-infiltrating TIA-1+ cytotoxic $\mathrm{T}$ cells but not FOXP3+ regulatory $\mathrm{T}$ cells predicts outcome in diffuse large B-cell lymphoma," British Journal of Haematology, vol. 137, no. 4, pp. 364-373, 2007.

[32] S. Piconese, P. Pittoni, A. Burocchi et al., "A non-redundant role for OX40 in the competitive fitness of Treg in response to IL-2," European Journal of Immunology, vol. 40, no. 10, pp. 2902-2913, 2010. 
[33] C. Tripodo, G. Gri, P. P. Piccaluga et al., "Mast cells and Th17 cells contribute to the lymphoma-associated proinflammatory microenvironment of angioimmunoblastic Tcell lymphoma," American Journal of Pathology, vol. 177, no. 2, pp. 792-802, 2010.

[34] A. Doganci, T. Eigenbrod, N. Krug et al., "The IL-6R $\alpha$ chain controls lung $\mathrm{CD} 4{ }^{+} \mathrm{CD} 25^{+}$Treg development and function during allergic airway inflammation in vivo," Journal of Clinical Investigation, vol. 115, no. 2, pp. 313-325, 2005.

[35] S. Wan, C. Xia, and L. Morel, "IL-6 produced by dendritic cells from lupus-prone mice inhibits $\mathrm{CD} 4^{+} \mathrm{CD} 25^{+} \mathrm{T}$ cell regulatory functions," Journal of Immunology, vol. 178, no. 1, pp. 271-279, 2007.

[36] X. Valencia, G. Stephens, R. Goldbach-Mansky, M. Wilson, E. M. Shevach, and P. E. Lipsky, "TNF downmodulates the function of human $\mathrm{CD} 4^{+} \mathrm{CD} 25$ hi T-regulatory cells," Blood, vol. 108, no. 1, pp. 253-261, 2006.

[37] D. Gratzinger, S. Zhao, R. J. Marinelli et al., "Microvessel density and expression of vascular endothelial growth factor and its receptors in diffuse large B-cell lymphoma subtypes," American Journal of Pathology, vol. 170, no. 4, pp. 1362-1369, 2007.

[38] A. Potti, A. K. Ganti, S. Kargas, and M. Koch, "Immunohistochemical detection of C-kit (CD117) and vascular endothelial growth factor (VEGF) overexpression in mantle cell lymphoma," Anticancer Research, vol. 22, no. 5, pp. 28992901, 2002.

[39] S. M. Smith, J. Anastasi, K. S. Cohen, and L. A. Godley, "The impact of MYC expression in lymphoma biology: beyond Burkitt lymphoma," Blood Cells, Molecules, and Diseases, vol. 45, no. 4, pp. 317-323, 2010.

[40] A. Tzankov, S. Heiss, S. Ebner et al., "Angiogenesis in nodal B cell lymphomas: a high throughput study," Journal of Clinical Pathology, vol. 60, no. 5, pp. 476-482, 2007.

[41] J. Ruan, K. Hajjar, S. Rafii, and J. P. Leonard, "Angiogenesis and antiangiogenic therapy in non-Hodgkin's lymphoma," Annals of Oncology, vol. 20, no. 3, pp. 413-424, 2009.

[42] T. Takahashi, H. Ueno, and M. Shibuya, "VEGF activates protein kinase C-dependent, but Ras-independent RafMEK-MAP kinase pathway for DNA synthesis in primary endothelial cells," Oncogene, vol. 18, no. 13, pp. 2221-2230, 1999.

[43] B. Barleon, S. Sozzani, D. Zhou, H. A. Weich, A. Mantovani, and D. Marmé, "Migration of human monocytes in response to vascular endothelial growth factor (VEGF) is mediated via the VEGF receptor flt-1," Blood, vol. 87, no. 8, pp. 3336-3343, 1996.

[44] B. L. Gruber, M. J. Marchese, and R. Kew, "Angiogenic factors stimulate mast-cell migration," Blood, vol. 86, no. 7, pp. 2488-2493, 1995.

[45] C. Sunderkotter, K. Steinbrink, M. Goebeler, R. Bhardwaj, and C. Sorg, "Macrophages and angiogenesis," Journal of Leukocyte Biology, vol. 55, no. 3, pp. 410-422, 1994.

[46] D. Ribatti, A. Vacca, A. Marzullo et al., "Angiogenesis and mast cell density with tryptase activity increase simultaneously with pathological progression in B-cell non-Hodgkin's lymphomas," International Journal of Cancer, vol. 85, no. 2, pp. 171-175, 2000.

[47] D. Ribatti, A. Vacca, B. Nico, E. Crivellato, L. Roncali, and F. Dammacco, "The role of mast cells in tumour angiogenesis," British Journal of Haematology, vol. 115, no. 3, pp. 514-521, 2001.

[48] S. Rafii, D. Lyden, R. Benezra, K. Hattori, and B. Heissig, "Vascular and haematopoietic stem cells: novel targets for anti-angiogenesis therapy?" Nature Reviews Cancer, vol. 2, no. 11, pp. 826-835, 2002.

[49] M. Grunewald, I. Avraham, Y. Dor et al., "VEGF-induced adult neovascularization: recruitment, retention, and role of accessory cells," Cell, vol. 124, no. 1, pp. 175-189, 2006.

[50] D. Gratzinger, S. Zhao, R. J. Tibshirani et al., "Prognostic significance of VEGF, VEGF receptors, and microvessel density in diffuse large B cell lymphoma treated with anthracyclinebased chemotherapy," Laboratory Investigation, vol. 88, no. 1, pp. 38-47, 2008.

[51] D. Ribatti, A. Vacca, B. Nico, M. Fanelli, L. Roncali, and F. Dammacco, "Angiogenesis spectrum in the stroma of B-cell non-Hodgkin's lymphomas. An immunohistochemical and ultrastructural study," European Journal of Haematology, vol. 56, no. 1-2, pp. 45-53, 1996.

[52] O. Bairey, Y. Zimra, E. Kaganovsky, M. Shaklai, E. Okon, and E. Rabizadeh, "Microvessel density in chemosensitive and chemoresistant diffuse large B-cell lymphomas," Medical Oncology, vol. 17, no. 4, pp. 314-318, 2000.

[53] K. N. Ganjoo, A. M. Moore, A. Orazi, J. A. Sen, C. S. Johnson, and C. S. An, "The importance of angiogenesis markers in the outcome of patients with diffuse large B cell lymphoma: a retrospective study of 97 patients," Journal of Cancer Research and Clinical Oncology, vol. 134, no. 3, pp. 381-387, 2008.

[54] T. M. Cardesa-Salzmann, L. Colomo, G. Gutierrez et al., "High microvessel density determines a poor outcome in patients with diffuse large B-cell lymphoma treated with rituximab plus chemotherapy," Haematologica, vol. 96, no. 7, pp. 996-1001, 2011.

[55] T. A. Baudino, C. McKay, H. Pendeville-Samain et al., "cMyc is essential for vasculogenesis and angiogenesis during development and tumor progression," Genes and Development, vol. 16, no. 19, pp. 2530-2543, 2002.

[56] A. Ruddell, P. Mezquita, K. A. Brandvold, A. Farr, and B. M. Iritani, "B lymphocyte-specific c-Myc expression stimulates early and functional expansion of the vasculature and lymphatics during lymphomagenesis," American Journal of Pathology, vol. 163, no. 6, pp. 2233-2245, 2003.

[57] U. E. Knies-Bamforth, S. B. Fox, R. Poulsom, G. I. Evan, and A. L. Harris, "c-Myc interacts with hypoxia to induce angiogenesis in vivo by a vascular endothelial growth factordependent mechanism," Cancer Research, vol. 64, no. 18, pp. 6563-6570, 2004.

[58] M. Baroudi, D. Corà, C. Bosia, M. Osella, and M. Caselle, "A curated database of miRNA mediated feed-forward loops involving MYC as master regulator," PLoS ONE, vol. 6, no. 3, Article ID e14742, 2011.

[59] J. Ruan, P. Martin, M. Coleman et al., "Durable responses with the metronomic rituximab and thalidomide plus prednisone, etoposide, procarbazine, and cyclophosphamide regimen in elderly patients with recurrent mantle cell lymphoma," Cancer, vol. 116, no. 11, pp. 2655-2664, 2010.

[60] S. Monestiroli, P. Mancuso, A. Burlini et al., "Kinetics and viability of circulating endothelial cells as surrogate angiogenesis marker in an animal model of human lymphoma," Cancer Research, vol. 61, no. 11, pp. 4341-4344, 2001.

[61] F. Bertolini, C. Dell'Agnola, P. Mancuso et al., "CXCR4 neutralization, a novel therapeutic approach for non-Hodgkin's lymphoma," Cancer Research, vol. 62, no. 11, pp. 3106-3112, 2002.

[62] B. Geiger, A. Bershadsky, R. Pankov, and K. M. Yamada, "Transmembrane extracellular matrix-cytoskeleton crosstalk," Nature Reviews Molecular Cell Biology, vol. 2, no. 11, pp. 793-805, 2001. 
[63] A. Bergamaschi, E. Tagliabue, T. Sørlie et al., "Extracellular matrix signature identifies breast cancer subgroups with different clinical outcome," Journal of Pathology, vol. 214, no. 3, pp. 357-367, 2008.

[64] M. R. Ng and J. S. Brugge, "A stiff blow from the stroma: collagen crosslinking drives tumor progression," Cancer Cell, vol. 16, no. 6, pp. 455-457, 2009.

[65] G. Lenz, G. Wright, S. S. Dave et al., "Stromal gene signatures in large-B-cell lymphomas," The New England Journal of Medicine, vol. 359, no. 22, pp. 2313-2323, 2008.

[66] H. W. Tun, D. Personett, K. A. Baskerville et al., "Pathway analysis of primary central nervous system lymphoma," Blood, vol. 111, no. 6, pp. 3200-3210, 2008.

[67] A. Rosenwald, G. Wright, W. C. Chan et al., "The use of molecular profiling to predict survival after chemotherapy for diffuse large-B-cell lymphoma," The New England Journal of Medicine, vol. 346, no. 25, pp. 1937-1947, 2002.

[68] T. R. Kyriakides and P. Bornstein, "Matricellular proteins as modulators of wound healing and the foreign body response," Thrombosis and Haemostasis, vol. 90, no. 6, pp. 986-992, 2003.

[69] S. Sangaletti and M. P. Colombo, "Matricellular proteins at the crossroad of inflammation and cancer," Cancer Letters, vol. 267, no. 2, pp. 245-253, 2008.

[70] S. M. Pupa, S. Ménard, S. Forti, and E. Tagliabue, "New insights into the role of extracellular matrix during tumor onset and progression," Journal of Cellular Physiology, vol. 192, no. 3, pp. 259-267, 2002.

[71] P. Y. Wai and P. C. Kuo, "Osteopontin: regulation in tumor metastasis," Cancer and Metastasis Reviews, vol. 27, no. 1, pp. 103-118, 2008.

[72] A. F. Chambers, S. M. Wilson, N. Kerkvliet, F. P. O’Malley, J. F. Harris, and A. G. Casson, "Osteopontin expression in lung cancer,” Lung Cancer, vol. 15, no. 3, pp. 311-323, 1996.

[73] K. A. Furger, R. K. Menon, A. B. Tuck, V. H. C. Bramwel, and A. F. Chambers, "The functional and clinical roles of osteopontin in cancer and metastasis," Current Molecular Medicine, vol. 1, no. 5, pp. 621-632, 2001.

[74] M. K. El-Tanani, "Role of osteopontin in cellular signaling and metastatic phenotype," Frontiers in Bioscience, vol. 1, no. 13, pp. 4276-4284, 2008.

[75] C. Chiodoni, M. P. Colombo, and S. Sangaletti, "Matricellular proteins: from homeostasis to inflammation, cancer, and metastasis," Cancer and Metastasis Reviews, vol. 29, no. 2, pp. 295-307, 2010.

[76] Y. H. Lin and H. F. Yang-Yen, "The osteopontin-CD44 survival signal involves activation of the phosphatidylinositol 3-kinase/Akt signaling pathway," Journal of Biological Chemistry, vol. 276, no. 49, pp. 46024-46030, 2001.

[77] R. S. Hauptschein, K. E. Sloan, C. Torella et al., "Functional proteomic screen identifies a modulating role for CD44 in death receptor-mediated apoptosis," Cancer Research, vol. 65, no. 5, pp. 1887-1896, 2005.

[78] S. A. Khan, A. C. Cook, M. Kappil et al., "Enhanced cell surface CD44 variant (v6, v9) expression by osteopontin in breast cancer epithelial cells facilitates tumor cell migration: novel post-transcriptional, post-translational regulation," Clinical and Experimental Metastasis, vol. 22, no. 8, pp. 663673, 2005.

[79] A. Tzankov, A. C. Pehrs, A. Zimpfer et al., "Prognostic significance of CD44 expression in diffuse large B cell lymphoma of activated and germinal centre B cell-like types: a tissue microarray analysis of 90 cases," Journal of Clinical Pathology, vol. 56, no. 10, pp. 747-752, 2003.
[80] A. Mantovani, P. Allavena, A. Sica, and F. Balkwill, "Cancerrelated inflammation," Nature, vol. 454, no. 7203, pp. 436444, 2008.

[81] A. D. Bradshaw and E. H. Sage, "SPARC, a matricellular protein that functions in cellular differentiation and tissue response to injury," Journal of Clinical Investigation, vol. 107, no. 9, pp. 1049-1054, 2001.

[82] V. H. C. Bramwell, A. B. Tuck, S. M. Wilson et al., "Expression of osteopontin and HGF/met in adult soft tissue tumors," Cancer Biology and Therapy, vol. 4, no. 12, pp. 1336-1341, 2005.

[83] A. B. Tuck, C. Hota, S. M. Wilson, and A. F. Chambers, "Osteopontin-induced migration of human mammary epithelial cells involves activation of EGF receptor and multiple signal transduction pathways," Oncogene, vol. 22, no. 8, pp. 1198-1205, 2003.

[84] D. N. Haylock and S. K. Nilsson, "Osteopontin: a bridge between bone and blood," British Journal of Haematology, vol. 134, no. 5, pp. 467-474, 2006.

[85] A. D. Bradshaw, "The role of SPARC in extracellular matrix assembly," Journal of Cell Communication and Signaling, vol. 3, no. 3-4, pp. 239-246, 2009.

[86] J. R. Infante, H. Matsubayashi, N. Sato et al., "Peritumoral fibroblast SPARC expression and patient outcome with resectable pancreatic adenocarcinoma," Journal of Clinical Oncology, vol. 25, no. 3, pp. 319-325, 2007.

[87] O. L. Podhajcer, L. G. Benedetti, M. R. Girotti, F. Prada, E. Salvatierra, and A. S. Llera, "The role of the matricellular protein SPARC in the dynamic interaction between the tumor and the host," Cancer and Metastasis Reviews, vol. 27, no. 4, pp. 691-705, 2008.

[88] N. A. Said, A. A. Elmarakby, J. D. Imig, D. J. Fulton, and K. Motamed, "SPARC ameliorates ovarian cancer-associated inflammation,” Neoplasia, vol. 10, no. 10, pp. 1092-1104, 2008.

[89] N. Said, I. Najwer, and K. Motamed, "Secreted protein acidic and rich in cysteine (SPARC) inhibits integrin-mediated adhesion and growth factor-dependent survival signaling in ovarian cancer," American Journal of Pathology, vol. 170, no. 3, pp. 1054-1063, 2007.

[90] P. P. Piccaluga, G. de Falco, M. Kustagi et al., "Gene expression analysis uncovers similarity and differences among Burkitt lymphoma subtypes," Blood, vol. 117, no. 13, pp. 3596-3608, 2011.

[91] S. Piconese, M. Costanza, C. Tripodo et al., "The matricellular protein SPARC supports follicular dendritic cell networking toward Th17 responses," Journal of Autoimmunity, vol. 37, no. 4, pp. 300-310, 2011

[92] A. Vacca, R. Ria, M. Presta et al., “ $\alpha(v) \beta(3)$ integrin engagement modulates cell adhesion, proliferation, and protease secretion in human lymphoid tumor cells," Experimental Hematology, vol. 29, no. 8, pp. 993-1003, 2001.

[93] U. Reuning, "Integrin $\alpha v \beta 3$ promotes vitronectin gene expression in human ovarian cancer cells by implicating rel transcription factors," Journal of Cellular Biochemistry, vol. 112, no. 7, pp. 1909-1919, 2011.

[94] N. Ahmed, C. Riley, G. Rice, and M. Quinn, "Role of integrin receptors for fibronectin, collagen and laminin in the regulation of ovarian carcinoma functions in response to a matrix microenvironment," Clinical and Experimental Metastasis, vol. 22, no. 5, pp. 391-402, 2005.

[95] J. Wang, J. Wu, J. Hong et al., "PKC promotes the migration of colon cancer cells by regulating the internalization and 
recycling of integrin $\alpha \mathrm{v} \beta 6$," Cancer Letters, vol. 311, no. 1, pp. 38-47, 2011.

[96] J. J. Grzesiak, H. S. T. Cao, D. W. Burton et al., "Knockdown of the $\beta(1)$ integrin subunit reduces primary tumor growth and inhibits pancreatic cancer metastasis," International Journal of Cancer, vol. 129, no. 12, pp. 2905-2915, 2011.

[97] I. Stamenkovic, "Extracellular matrix remodelling: the role of matrix metalloproteinases," Journal of Pathology, vol. 200, no. 4, pp. 448-464, 2003.

[98] S. Curran and G. I. Murray, "Matrix metalloproteinases in tumour invasion and metastasis," Journal of Pathology, vol. 189, no. 3, pp. 300-308, 1999.

[99] A. E. Kossakowska, A. Hinek, D. R. Edwards et al., "Proteolytic activity of human non-Hodgkin's lymphomas," American Journal of Pathology, vol. 152, no. 2, pp. 565-576, 1998.

[100] A. E. Kossakowska, D. R. Edwards, C. Prusinkiewicz et al., "Interleukin-6 regulation of matrix metalloproteinase (MMP-2 and MMP-9) and tissue inhibitor of metalloproteinase (TIMP-1) expression in malignant non-Hodgkin's lymphomas," Blood, vol. 94, no. 6, pp. 2080-2089, 1999.

[101] T. Sato, A. Ito, and Y. Mori, "Interleukin 6 enhances the production of tissue inhibitor of metalloproteinases (TIMP) but not that of matrix metalloproteinases by human fibroblasts," Biochemical and Biophysical Research Communications, vol. 170, no. 2, pp. 824-829, 1990.

[102] A. E. Kossakowska, S. J. Urbanski, and D. R. Edwards, "Tissue inhibitor of metalloproteinases-1 (TIMP-1) RNA is expressed at elevated levels in malignant non-Hodgkin's lymphomas," Blood, vol. 77, no. 11, pp. 2475-2481, 1991.

[103] L. Guedez, L. Courtemanch, and M. Stetler-Stevenson, "Tissue inhibitor of metalloproteinase (TIMP)-1 induces differentiation and an antiapoptotic phenotype in germinal center B cells," Blood, vol. 92, no. 4, pp. 1342-1349, 1998.

[104] J. W. Choi, J. S. An, J. H. Lee, E. S. Lee, K. H. Kim, and Y. S. Kim, "Clinicopathologic implications of tissue inhibitor of metalloproteinase-1- positive diffuse large B-cell lymphoma," Modern Pathology, vol. 19, no. 7, pp. 963-973, 2006.

[105] C. Fang, D. X. Zhu, H. J. Dong et al., "Serum microRNAs are promising novel biomarkers for diffuse large B cell lymphoma," Annals of Hematology. In press. 


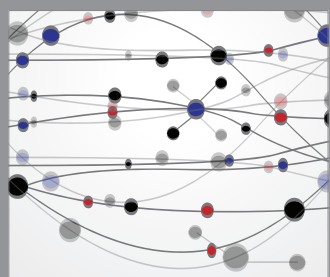

The Scientific World Journal
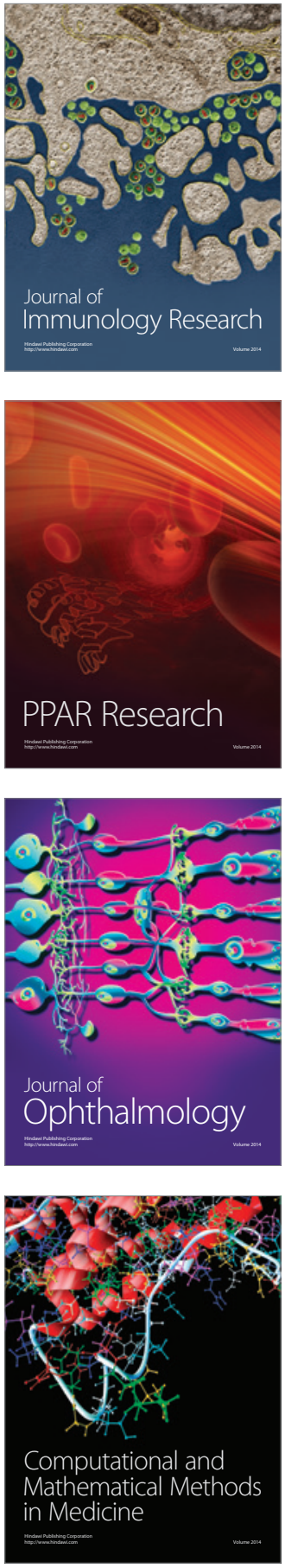

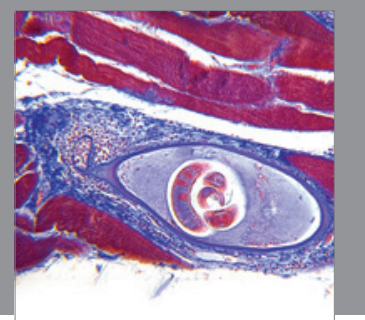

Gastroenterology

Research and Practice
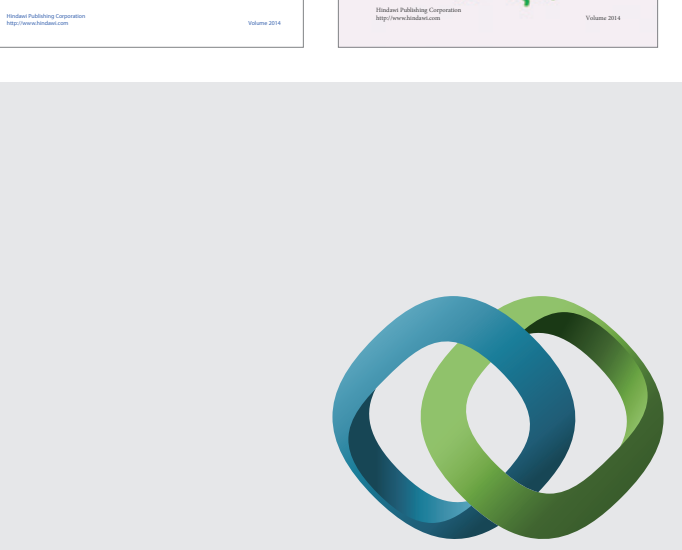

\section{Hindawi}

Submit your manuscripts at

http://www.hindawi.com
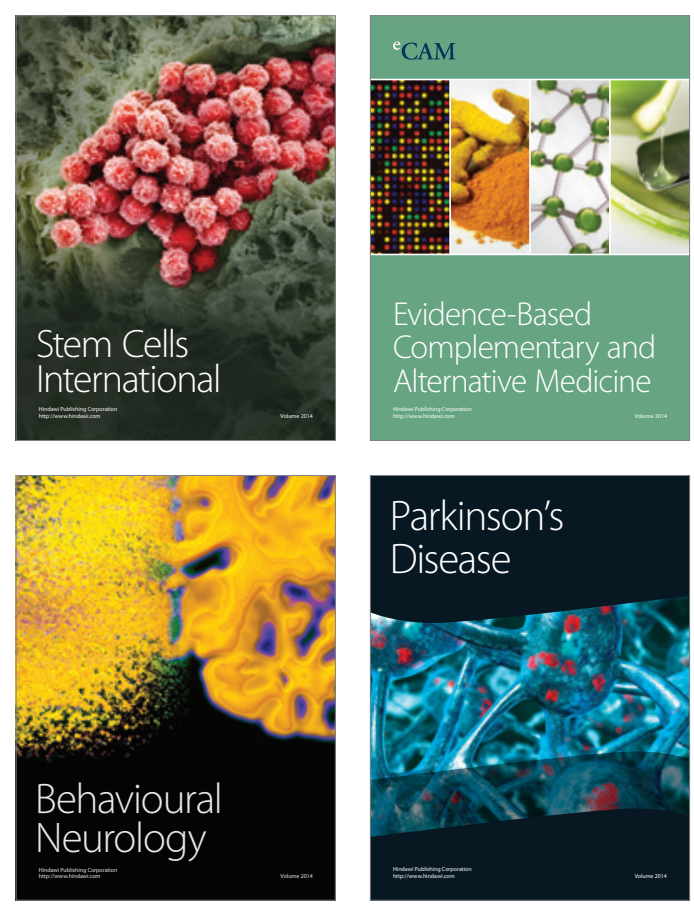

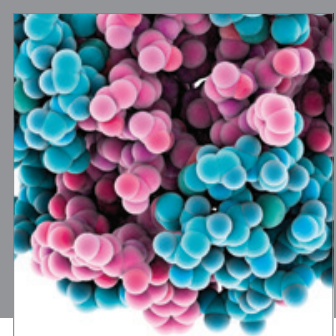

Journal of
Diabetes Research

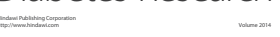

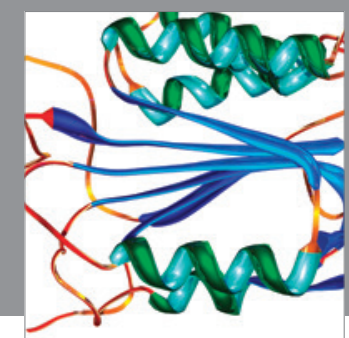

Disease Markers
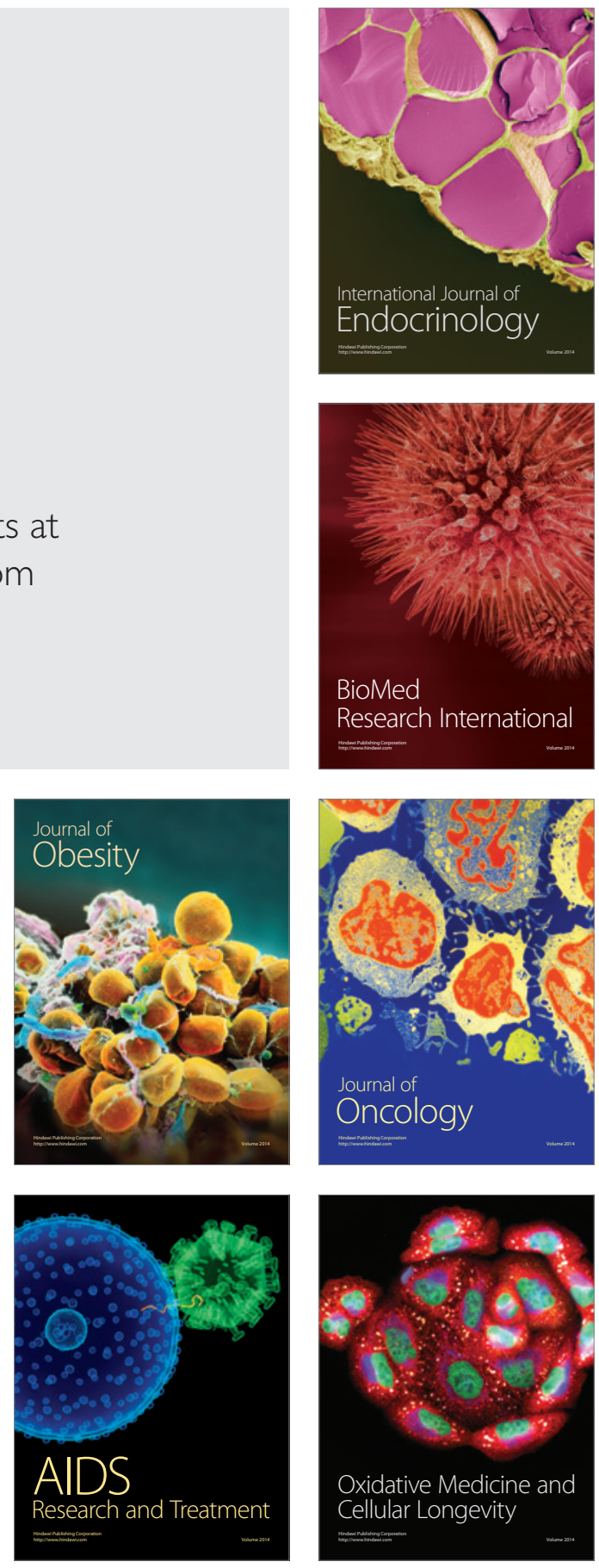